\title{
A Theory Explaining Biological Correlates of Criminality
}

\author{
Lee Ellis \\ Minot State University, USA
}

\begin{abstract}
Despite major advances in understanding the biological basis of human behaviour, the most popular theories of criminal behaviour remain restricted to those that consider only learning and social environmental variables. All of these strictly environmental theories have difficulty explaining why neurological, hormonal, and other biological factors would be related to criminal behaviour, yet evidence for links between such biological factors and criminality has grown. This article puts forward a theory that takes account of biological as well as environmental factors, and predicts that variables such as age, gender and social status will be associated with offending probabilities. It is argued that male sex hormones operating on the human brain increase the probability of competitive/ victimizing behaviour. This type of behaviour (or behavioural tendency) is hypothesized to exist along a continuum, with 'crude' (criminal) forms at one end and 'sophisticated' (commercial) forms at the other. Individuals with the greatest capacities to learn and plan will move rapidly after puberty from criminal to non-criminal forms of competitive/victimizing behaviour. The theory predicts among other things that serious criminality will be concentrated in adolescent and young adult males of low social status. Evidence is reviewed on links between criminality and various biological variables, including testosterone, mesomorphy, maternal smoking during pregnancy, hypoglycemia, epilepsy, altered heart rate and skin conductivity, cortisol, serotonin, monoamine oxidase, and certain brainwave patterns.
\end{abstract}

\section{KEY WORDS}

Biological Correlates / Criminological Theory / Evolution / Female Choice / Sex Differences / Social Status. 


\section{A theory explaining biological correlates of criminality}

This article will summarize the evidence showing that various biological factors are associated with criminal behaviour and will offer explanations for these links. It is probably because they have little training in biology, that most criminologists have little awareness of these biological factors. That needs to change in light of growing evidence that human behaviour, including behaviour defined as criminal, is heavily influenced by each individual's uniquely functioning brain as well as hormonal factors which alter brain functioning.

I begin by offering a theory of criminal behaviour that takes in to account both biological and social environmental influences. Next, I make deductions from the theory to explain why several biological variables would be associated with criminality.

\section{The evolutionary neuroandrogenic theory of criminal behaviour}

The theory presented here, termed the evolutionary neuroandrogenic theory (ENA), chiefly aims to explain offences that directly harm others either by injuring them physically or by depriving them of their property. The theory does not specifically aim to explain victimless crimes.

Two main propositions lie at the heart of ENA theory. The first proposition addresses evolutionary issues by asserting that aggressive and acquisitive criminal behaviour evolved as an aspect of human reproduction, especially among males. The second proposition is concerned with identifying the neurochemistry responsible for increasing the probability of aggressive and acquisitive criminal behaviour among males relative to females. The theory maintains that sex hormones alter male brain functioning in ways that promote what will be called competitivelvictimizing behaviour, which includes criminal behaviour directed at others along with a range of non-criminal behaviours to be specified below.

The concept of competitive/victimizing behaviour is illustrated in Table 1. At one end of the continuum are acts that intentionally and directly either injure fellow societal members or dispossess them of their property. In all societies with written laws, these obviously harmful acts are criminalized (Ellis and Walsh 2000: 8). At the other end of the competitive/ victimizing continuum are acts that make no profits on the sale of goods or services, although those who administer and maintain the organizations under which they operate usually receive much higher wages than do those who provide most of the day-to-day labour. In a purely socialist economy, 
Table 1 A continuum of victimizing behaviour (reflecting competitive/victimizing tendencies)

\begin{tabular}{|c|c|c|c|c|c|}
\hline The continuum & very crude ----- & --------------------- & intermediate ---- & V & sophisticated \\
\hline $\begin{array}{l}\text { Probability of } \\
\text { being }\end{array}$ & virtually certain & --------------------- & intermediate ----- & exc & lingly unlikely \\
\hline Examples & $\begin{array}{c}\text { Violent \& } \\
\text { property } \\
\text { offences } \\
\text { ('street crime') }\end{array}$ & $\begin{array}{l}\text { Embezzlement, } \\
\text { fraud ('white } \\
\text { collar crime') }\end{array}$ & $\begin{array}{c}\text { Deceptive } \\
\text { business } \\
\text { practices, price } \\
\text { gouging }\end{array}$ & $\begin{array}{l}\text { Profit-making } \\
\text { commerce }\end{array}$ & $\begin{array}{l}\text { Non-profit- } \\
\text { making } \\
\text { commerce }\end{array}$ \\
\hline
\end{tabular}

the latter type of minimally competitive activities is all that is allowed; all other forms are criminalized. A capitalist economy, on the other hand, will permit profit-making commerce and often even commerce that involves significant degrees of deception. With the concept of competitive/ victimizing behaviour in mind, the two propositions upon which the theory rests can now be described.

\section{The evolutionary proposition}

Throughout the world, males engage in aggressive and acquisitive crimes (especially those involving violence) to a greater extent than do females (Ellis and Walsh 2000: 102-6). To explain this observation, ENA theory maintains that for evolutionary reasons, female mating preferences play a pivotal role. The nature of this mating preference is that females consider social status criteria more than males do in making mate choices (Ellis 2001). The evidence suggesting such a gender difference comes from studies of numerous societies (Kemper and Bologh 1980; Buss et al. 1990; Davis 1990).

From an evolutionary standpoint, this phenomenon, known as female choice, has served to increase the chances of females mating with males who are reliable providers of resources, allowing females to focus more of their time and energy on bearing offspring. Another consequence has been that female choice has made it possible for males who are status strivers to pass on their genes at higher rates than males who are not. The reinforcment of the view that female preferences for status-striving males has evolutionary roots is evidence that similar mating biases exist among females of other mammalian species. Specifically, in most other mammals, 
females are more likely to mate with relatively dominant males than with subordinate males (Ellis 1995).

According to ENA theory, female preferences for status-striving males have caused most males to devote considerable time and energy to competing for resources, an endeavour that often victimizes others. In other words, natural selection pressure on females to prefer status-striving mates has resulted in males with a distinct inclination toward competitive/ victimizing behaviour.

As noted earlier, competitive/victimizing behaviour is assumed to exist along a continuum at one end of which are acts that directly harm others physically or deny them access to their property. The other end of the competitive/victimizing continuum consists of acts that provide goods and services to others. Even though such commercial forms of the behaviour can cause much greater harms than those inflicted by most violent and property crimes (for example, when dangerous products are manufactured and sold), commercial forms are far less likely to be criminalized.

ENA theory maintains that the brains of males have been selected for exhibiting competitive/victimizing behaviour to a greater extent than the brains of females, and that one of the manifestations of this evolved sex difference is that males are more prone than females toward aggressive and acquisitive crime.

Theoretically, the same natural selection pressure that has resulted in the evolution of competitive/victimizing behaviour has also favoured males who flaunt and even exaggerate their capacities as providers. A more unpleasant consequence of the female bias for mates who are good providers is a male tendency to use deceptive or forceful copulation tactics (Ellis 1989; Thornhill and Palmer 2000). Deductions from this line of reasoning are that rape will always be more common among males than among females and that it will be especially common among males whose prospects of becoming stable providers of resources are relatively poor.

ENA theory leads one to expect a great deal of complexity in the social system surrounding criminal behaviour. Much of this complexity is captured by the evolutionary concept of counter-strategies. Theoretically, an example of a counter-strategy to crude forms of competitive/victimizing behaviour is the evolution of the criminal justice system (Ellis 1990). All societies in which writing has evolved have instituted criminal justice systems in order to circumscribe and enforce distinctions between acceptable and unacceptable forms of competitive/victimizing behaviour.

As with any theory which is founded on neo-Darwinian thinking, ENA theory assumes that genes are responsible for substantial proportions of the variation in the traits being investigated. In the present context, the average male is assumed to have a greater genetic propensity toward 
competitive/victimizing behaviour than is true for the average female. However, this assumption must be reconciled with the fact that males and females share nearly all of their genes. The only possible way for the theory to be correct is for some of the genes that promote criminality (along with other forms of competitive/victimizing behaviour) to be located on the one chromosome that males and females do not share - the Y-chromosome. This implication is discussed now in more detail.

\section{The neuroandrogenic proposition}

The second proposition of ENA theory is that three different aspects of brain functioning affect an individual's chances of criminal offending. They all do so by promoting the tendencies toward competitive/victimizing behaviour. Two additional neurological factors are hypothesized to help to inhibit offending by speeding up the acquisition of sophisticated forms of competitive/victimizing behaviour.

Testosterone is hypothesized to play a central role in promoting competitive/victimizing behaviour. For this reason, it is important to describe how testosterone impacts brain functioning through its antecendent effects upon genital structures: Genes located on the Y-chromosome profoundly alter the course of genital development (Ellis and Ames, 1987). For example, during the first few months of gestation, genes on the Ychromosome function to convert would-be ovaries into testes instead. Once the testes have developed, they produce substantial quantities of testosterone along with other 'male hormones', collectively called androgens. As shown in Figure 1, females also produce testosterone, but males produce it

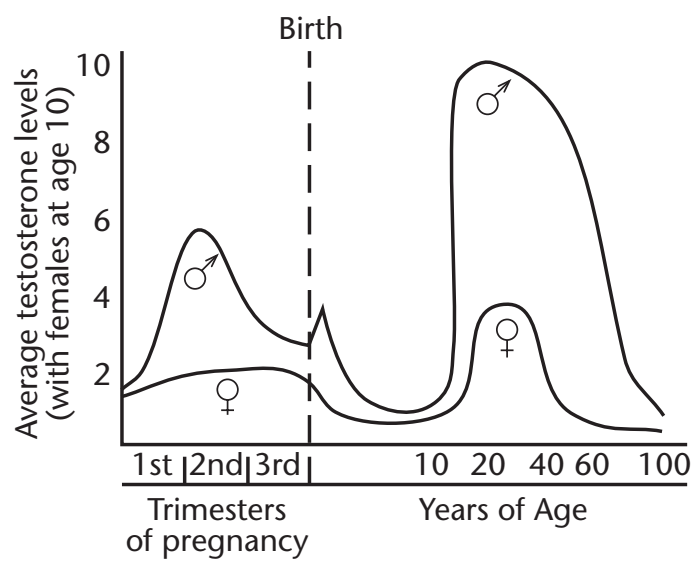

Figure 1 Testosterone levels in human males and females from conception through old age 
in larger quantities. The quantities produced vary considerably throughout the life of both sexes.

Figure 1 shows testosterone production occurring in two distinct phases, particularly in the case of males: the organizational (or perinatal) phase and the activational (or postpubertal) phase. Experiments with laboratory animals have shown that testosterone affects brain functioning throughout life, although the most permanent and irreversible effects occur perinatally (Thornton and Goy 1986; Compaan et al. 1993). Setting aside a number of technical qualifications, high (male-typical) levels of testosterone masculinize the brain, while low levels typical of females allow the brain to remain in its default feminine mode (Ellis and Ames 1987; Burr 1993: 51).

As shown in Figure 1, large quantities of testosterone and other androgens are produced by the male testes beginning with the onset of puberty. At that point, androgens flood the brain, thereby activating male features built into the brain during foetal development. ENA theory asserts that competitive/victimizing behaviour is central to this neurological sexual differentiation. The underlying neurology will now be described.

\section{Promoting competitive/victimizing behaviour}

ENA theory asserts that androgens increase the probability of competitive/ victimizing behaviour by changing the brain in three fairly specific ways. The first involves decreasing an individual's sensitivity to adverse environmental consequences resulting from his or her own competitive/victimizing behaviour. This lowered sensitivity is accomplished by inclining the brain to be suboptimally aroused (Ellis 1987, 1995). Suboptimal arousal manifests itself in lowered sensitivity to pain and in seeking elevated levels of sensory stimulation.

The second way brains promote competitive/victimizing behaviour according to ENA theory is by inclining the limbic system to go into a state of seizure more readily, especially under stressful conditions. At the extreme, these seizures include such clinical conditions as epilepsy and Tourette's syndrome. Less extreme manifestations of limbic seizure are known as episodic dyscontrol and limbic psychotic trigger reaction (Kandel and Freed 1989: 406; Creaby et al. 1993; Pontius 2004). These latter patterns include sudden bursts of rage and other negative emotions, which often trigger forceful actions against any opponent who is perceived to have acted provocatively. Third, ENA theory asserts that androgen exposure causes neocortical functioning to be less concentrated in the left (language-dominated) hemisphere and to shift more towards the right hemisphere (Shucard et al. 1981: 93; Reite et al. 1993). As a result of this 
rightward shift in neocortical functioning, males rely less on languagebased reasoning, emphasizing instead reasoning which involves spatial and temporal calculations of risk and reward probabilities. In line with this theory are intriguing new research findings based on functional magnetic resonance imaging (fMRI) which suggest that the seat of empathy-based moral reasoning is primarily in the left hemisphere (Moll et al. 2002). As predicted by ENA theory, empathy-based moral reasoning seems to be less pronounced in males than in females (Shoe et al. 1996; Badger et al. 1998). It has been argued that empathy-based moral reasoning is more likely to prevent criminal behaviour that constitutes a direct attack on people and property than is justice-based moral reasoning. Predictably, the latter is more characteristic of males than of females (Gilligan, 1982).

ENA theory proposes that the three androgen-enhanced brain processes just described have evolved in males more than in females because these processes contribute to competitive/victimizing behaviour. This flows from the more basic proposition that competitive/victimizing behaviour has evolved in males more than in females because it facilitates male reproductive success more than it facilitates female reproductive success.

\section{Inhibiting criminal forms of competitive/victimizing behaviour}

With regard to the inhibiting aspects of brain functioning, two factors are theoretically involved. One has to do with learning ability and the other entails foresight and planning ability.

Concerning the first factor, ENA theory assumes that as a result of both genetic and environmental factors, the capacity to learn has a neurological foundation that is not uniformly distributed. In this regard, recent MRI brain scans have revealed a substantial positive correlation (above .40) between paper-and-pencil measures of IQ and overall brain size (Ellis 1994: 155; Schoenemann et al. 2000). Also, research has indicated that 'more intelligent brains' process incoming sensory input at faster rates and with less metabolic energy expenditure than 'less intelligent brains', a phenomenon named neural efficiency (Fidelman 1992; Neubauer et al. 2004).

According to ENA theory, the ability to learn will be correlated with the speed with which males make the transition from crude to sophisticated forms of competitive/victimizing behaviour. This means that intelligence and other measures of learning ability should be inversely associated with persistent involvement in criminal behaviour. Likewise, neurological underpinnings of intelligence such as brain size and neural efficiency should also correlate negatively with persistent offending. These predictions apply only to persistent offending directed at people and property, with a much 
weaker link to occasional delinquency and possibly none at all with victimless criminality.

The evidence bearing on the above predictions is thus far largely confined to scores on traditional IQ tests. In accordance with predictions, studies indicate that intelligence is correlated inversely with offending, particularly in the case of persistent violent and property crime and least so with regard to youthful delinquency, especially if drug offences predominate (Ellis and Walsh 2003).

Research is needed to determine if the neurological underpinnings of intelligence are associated with criminality. A recent study did find that children who were diagnosed with attention deficit hyperactivity disorder (ADHD) - which is statistically predictive of offending later in life - had significantly smaller brains than did non-ADHD children (Castellanos et al. 2002).

The frontal lobes, especially their prefrontal regions, play a vital role in coordinating complex sequences of actions intended to accomplish longterm goals. These prefrontal regions monitor the brain's limbic region, where most emotions reside (Davidson, Cave and Sellner 2000: 592; Strayhorn 2002: 11). Then the prefrontal regions devise plans for either maximizing pleasant emotions or minimizing unpleasant ones (Fuster 1995; Tomarken and Keener 1998: 401). In other words, for the brain to integrate experiences into well-coordinated and feedback-contingent strategies for reaching long-term goals, the frontal lobes perform what has come to be called executive cognitive functioning (Barkley et al. 1992; Fishbein 2003). Moral reasoning often draws heavily on executive cognitive functioning since it often requires anticipating the long-term consequences of one's actions for oneself and for others (Anderson et al. 1999).

Factors that can have an impact on executive cognitive functioning include genetics, prenatal complications, and various types of physical and chemical trauma throughout life (Barkley 1990; Mann 1995: 1922). According to ENA theory, ineffective executive cognitive functioning contributes to criminal behaviour. Similar ideas have been put forward in recent years by several other researchers (e.g., Raine 1993; Miller et al. 1997; Kiehl et al. 2001; Fishbein 2003).

To summarize, ENA theory asserts that three aspects of brain functioning promote competitive/victimizing behaviour, the crudest forms of which are aggressive crimes and those directed at physical property. At least partially counterbalancing these androgen-promoted tendencies are high intelligence and efficient executive cognitive functioning. These latter two factors affect the speed with which individuals quickly learn to express their competitive/victimizing tendencies in sophisticated rather than crude ways. Sophisticated expressions are less likely to elicit retaliation by 
victims, their relatives, and the criminal justice system than are crude ones. Males with lower intelligence and with less efficient executive cognitive functioning will therefore show higher rates of criminal behaviour directed at people and their physical property than those with higher intelligence and more efficient executive cognitive functioning. Figure 2 (over) presents ENA theory in diagrammatic form.

\section{Correlates of criminal behaviour}

Correlates of crime are variables that have been investigated repeatedly with reference to criminal behaviour and found to exhibit consistent (or at least fairly consistent) relationships with such behaviour. The correlates to be examined here are of a biological nature, all of which are virtually impossible to explain from a strictly environmentalist perspective.

Twelve biological correlates of crime with special relevance to ENA theory are discussed below. These correlates are testosterone, mesomorphy, maternal smoking during pregnancy, hypoglycemia, epilepsy, heart rate, skin conductivity, cortisol, serotonin, monoamine oxidase, slow brainwave patterns, and P300 amplitude. The full extent of the evidence surrounding these correlates is beyond the scope of this article; interested readers may consult Ellis and Walsh (2000, Chapter 9) along with Ellis (2000) for complete documentation.

\section{Testosterone}

Testosterone plays a central role in ENA theory of criminality, and the theory predicts that correlations will be found between testosterone and criminal behaviour. However, the nature of these correlations will not involve a simple one-to-one correspondence between an individual's crime probability and the amount of testosterone in his/her body at any given point in time.

Earlier, a distinction was made between the organizational and activational effects of testosterone on brain functioning, and it was noted that the most permanent and irreversible effects of testosterone occur perinatally, not postpubertally. For this reason alone, testosterone levels circulating in the blood stream or in saliva following puberty may have little direct correlation with neurological levels, especially within each sex. Therefore, one should not expect to find a strong correlation between blood or saliva levels of testosterone among, say, 20-year-old males and the number of offences they have committed even though testosterone levels in the brain at various stages in development are quite influential on offending probabilities. 


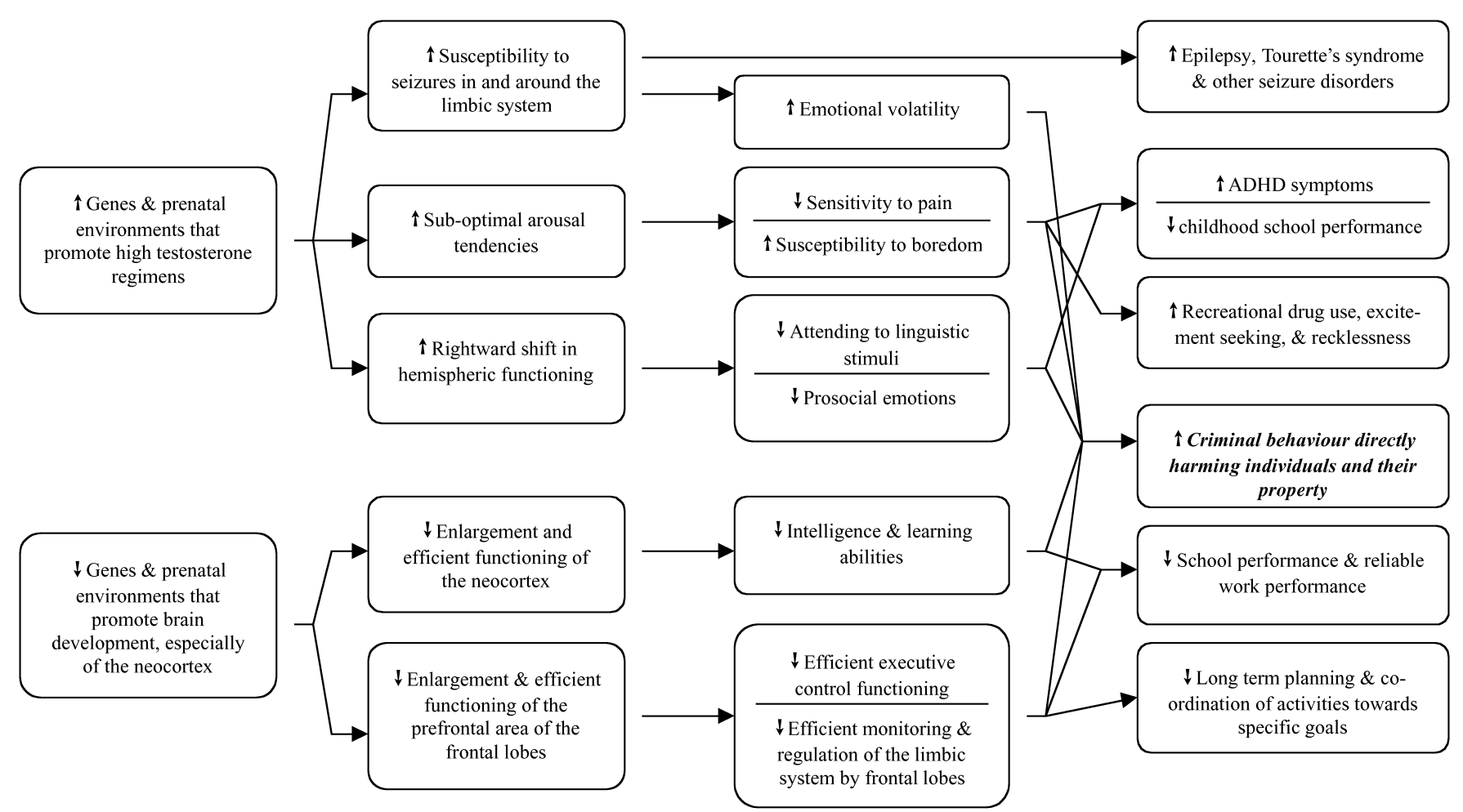

Figure 2 A graph representing the main elements of the neurological portion of the ENA theory of criminal/antisocial behaviour 
Numerous studies have investigated the possible relationship between blood levels or saliva levels of testosterone and involvement in criminal behaviour, and most have found modest positive correlations (usually between .20 and .25) (Ellis and Walsh 2000: 284). Nearly all of the exceptions involve juvenile delinquency, where the research has yielded mixed correlations. More precisely, all 11 studies involving adults have reported a modest but significant positive testosterone-offending relationship, while only three of five studies of adolescents did so, and one actually reported a significant negative relationship (Ellis 2000: 99).

Additional evidence of a connection between testosterone and aggressive forms of criminality comes from a recent study of domestic violence, where offending males had higher levels of saliva testosterone than did males with no history of such violence (Soler et al. 2000: 735). Furthermore, a study of boys in a Spanish elementary school revealed that those who played most aggressively exhibited higher testosterone levels than did their less aggressive peers (Sanchez-Martin et al. 2000).

Overall, it is safe to generalize that circulating testosterone levels exhibit a modest positive association with male offending probabilities, particularly in the case of adult violent and property offences. This conclusion is not predicted by any environmental theory of criminal behaviour but is quite consistent with ENA theory. Because male testosterone levels are vastly greater than those of females (see Figure 1), ENA theory's assertion that brain exposure to testosterone is responsible for much of the universal sex difference in criminality is also consistent with the findings regarding intra-male variations in this hormone.

\section{Mesomorphy}

Body types exist in three extreme forms. These are sometimes represented with a bulging triangle. Most people are located in the centre of the triangle, exhibiting what is termed a basically balanced body type. At one corner of the triangle are persons who are extremely muscular, especially in the upper body, called mesomorphs. Ectomorphs occupy a second corner. Individuals with this body type are unusually slender and non-muscular. In the third corner, one finds endomorphs, individuals who are overweight and have little muscularity.

Eight studies of the relationship between body types and criminality/ delinquency have been published. All of them have concluded that offending probabilities are higher among individuals who exhibit a mesomorphic body type than either of the two other extreme body types (reviewed by Ellis 2000: 97). In other words, while the distribution of body types for general populations are concentrated in the middle of the bulging triangle 
and then gradually taper out to the outer extremities, among criminal populations the mode is shifted significantly toward the mesomorphic corner of the triangle. This same tendency was found among males who were diagnosed with antisocial personality disorder (Hartl et al. 1982: 494).

ENA theory explains this well-established relationship by noting that testosterone affects more than the brain; it also enhances muscle tissue, especially in the upper part of the body (Bhasin et al. 1996). According to ENA theory, mesomorphic males are even more crime-prone than males in general because brain exposure to testosterone is positively correlated with muscle tissue exposure. This is likely to be true regarding both perinatally and postpubertally.

\section{Maternal smoking during pregnancy}

Since the early 1990s, six studies have been published regarding a link between maternal smoking during pregnancy and offending behaviour among offspring. Four of these studies indicate that offspring of women who smoke during pregnancy have an elevated probability of being delinquent (Bagley 1992; Rantakallio et al. 1992) or criminal (Brennan et al. 1999; Rasanes et al. 1999). The other two pertinent studies rendered qualified support for such a relationship (Gibson and Tibbetts 1998; Gibson et al. 2000).

ENA theory can explain these findings in any of three ways. One explanation involves assuming that foetal exposure to carbon monoxide and other neurotoxins found in cigarette smoke disrupt brain development in ways that adversely affects IQ or executive cognitive functioning, thereby making it more difficult for offspring to maintain their activities within prescribed legal boundaries later in life.

Another possibility is that some of the genes that promote involvement in criminal behaviour may also contribute to nicotine addiction. In this regard, nicotine appears to affect the reticular formation in and around the upper brain stem, which plays an important role in arousal control (Pritchard 1991: 1191; Polich and Kok 1995: 126). Furthermore, genes that help to regulate various neurotransmitters and their cellular receptor sites have been implicated in most forms of addiction (Comings et al. 1995; Muramatsu et al. 1996). If some of the same genes that affect criminal behaviour also affect susceptibility to tobacco addiction, one would expect to find a correlation between maternal tobacco use and offspring criminality. In fact, a recent study reported evidence that the link between childhood conduct disorders (a frequent precursor to later criminality) and maternal smoking was substantially attributable to some mutual genetic influences (Maughan et al. 2004). 
Finally, both intelligence and executive cognitive functioning may impact one's tendency to avoid tobacco use and/or addiction as well as avoid involvement in criminal behaviour. If so, inter-generational correlations should exist between maternal smoking and offspring offending behaviour unless one statistically controlled for inter-generational concordance in intelligence and executive cognitive functioning.

\section{Hypoglycemia}

Glucose, a type of natural sugar, is the main fuel used by the brain. The production of glucose is largely regulated by the pancreas in response to chemical messages from a portion of the brain called the hypothalamus. When the hypothalamus senses that glucose levels are becoming too high or too low, it sends chemical instructions to the pancreas to either curtail or increase production of glucose by regulating the amount of insulin released into the blood system. In most people, this feedback regulatory process helps to maintain brain glucose at remarkably stable levels.

For a variety of reasons, some people have difficulty stabilizing brain glucose levels. These people are said to suffer from hypoglycaemia. Although the prefix hypo means low, hypoglycaemia is best thought of as a condition of instability in glucose levels, rather than simply being too low (Bonnet and Pfeiffer 1978: 197; Chollar 1988: 33). Dramatic fluctuations in brain glucose can cause temporary disturbances in thoughts and moods, with the most common symptoms being confusion, difficulty concentrating, and irritability (Adlersberg and Dolger 1939: 1805; Virkkunen 1988: 153).

Since the 1970s, four studies have been conducted to determine if a relationship exists between hypoglycaemia and the probability of people committing adult crime, especially of a violent nature (Groesbeck et al. 1975; Yaruara-Tobias and Neziroglu 1975; Virkkunen and Huttunen 1982; Virkkunen 1986). In addition, two studies have looked for statistical links between hypoglycaemia and the antisocial personality disorder (Virkkunen 1982; Virkkunen 1983). All of these studies have concluded that significant positive relationships exist. Therefore, while hypoglycaemia is a rare condition, affecting less than one percent of the general population, its prevalence in populations of violent offenders has been shown to be significantly elevated.

To explain such a connection, ENA theory draws attention to the importance of unfettered communication between the various parts of the brain in order to maintain control over one's emotions. In particular, if the frontal lobes receive distorted signals from the limbic system, bizarre 
types of behavioural responses sometimes result, including responses that are violent and antisocial.

\section{Epilepsy}

Epilepsy is a neurological disorder typified by seizures. These seizures are tantamount to 'electrical storms' in the brain. While people vary in genetic susceptibilities, seizures are usually induced by environmental factors such as physical injuries to the brain, viral infections, birth trauma, and exposure to various chemicals (Cummings 1985: 99; Berenson et al. 1994; De Riu et al. 1995; Lanska and Lanska 1996). Seizures may also be triggered by hormonal changes associated with hypoglycaemia.

The main behavioural symptoms of epilepsy are known as convulsions (or fits), although not all epileptics have full-blown convulsive episodes. Mild epileptic episodes may manifest themselves as little more than a momentary pause in an on-going activity accompanied by a glazed stare. Seizures that have little to no noticeable debilitating effects on coordinated movement are called subconvulsive (or subclinical) seizures.

Studies of human populations have shown that epilepsy affects only about one in every 150 to 200 persons (Rose et al. 1987: 330). In prison populations, however, the rate of epilepsy is around one in 50, at least three-times higher than in the general population (Ellis 1987: 504). Epilepsy appears to be especially high among adults with repeated convictions for violent offences (Okasha et al. 1975; Mungas 1983; Mendez et al. 1993). Most studies of youthful delinquency, however, have found no statistical association with epilepsy (Gross and Kaltenback 1975; Rantakallio et al. 1995; for an exception see Fernando 1965).

From the perspective of ENA theory, links between epilepsy and violent offending can be explained by noting that very basic and primitive emotional responses sometimes emanate from the limbic region of the brain. While seizures in motor control centres are most likely to receive a diagnosis of epilepsy, seizures have a tendency to gradually engulf adjacent regions of the brain. This implies that some seizures in motor control centres can eventually spread to the limbic region.

As far as physiological mechanisms are concerned, ENA theory leads to the hypothesis that testosterone contributes to seizures, including subconvulsive seizures. The evidence pertaining to this hypothesis is mixed, suggesting that testosterone can actually have either promoting or inhibiting effects on seizure susceptibility, depending on the type of seizure and the instigating agent (reviewed by Smith et al. 2002). 


\section{Resting heart and pulse rates}

Heart and pulse rates rise in response to strenuous exercise along with stressful and frightening experiences. Studies have shown that on average the resting heart and pulse rates of convicted offenders are lower than those of persons in general. This is true for adult offenders (Raine et al. 1995; Farrington 1997: 94; Mezzacappa et al. 1997: 463) as well as juvenile delinquents (Wadsworth 1976; Raine and Venables 1984). The same pattern holds true regarding self-reported offending (Raine and Jones 1987), childhood conduct disorders (Rogeness et al. 1990; Kindlon et al. 1995), and adult psychopathy (Hare 1982; Raine 1988).

The above cited studies have used a variety of methodologies. For example, most have measured heart and pulse rates during roughly the same time frame as they assessed involvement in offending, although at least one study was conducted prospectively in the sense that the heart and pulse rates were measured a dozen years before criminal involvement was assessed (Raine et al. 1995). Other studies have indicated that the heart and pulse rates of delinquents and criminals rise more slowly in response to mild physical exertion than is true for people in general (Raine, Venables and Williams 1990a, 1990b; Raine et al. 1995).

ENA theory would account for these relationships by stipulating that both low heart and low pulse rates are physiological indicators of suboptimal arousal. Such arousal levels should incline individuals to seek more intense stimulation and to tolerate unpleasant environmental feedback to a greater extent than individuals with normal or superoptimal arousal under most circumstances.

\section{Skin conductivity (galvanic skin response)}

Sweat contains high concentrations of sodium, which is a good electrical conductor. A device called a Galvanic Skin Response (GSR) meter was developed nearly a century ago to monitor palm sweat. The GSR works by measuring electrical impulses passing through our bodies from one electrode to another. Thus, by putting ones fingers on two unconnected electrodes of a GSR device one completes an electrical circuit through which imperceptible amounts of electricity flow. Temperature obviously affects how much people sweat, but so too do emotions. The more intense one's emotions become (especially those of fear and anger), the more one will sweat, and thus the stronger will be the readings on the GSR meter.

Numerous studies have examined the possibility that persons with the greatest propensities toward criminal behaviour have distinctive skin conductivity patterns. These studies suggest that both juvenile and adult offenders exhibit lower skin conductivity under standard testing conditions 
than do people in general (Fox and Lippert 1963; Siddle et al. 1976; Buikhuisen et al. 1989; Raine et al. 1996). As in the case of heart and pulse rates, ENA theory can account for such findings by hypothesizing that low GSR readings especially under stressful testing conditions are another indication of suboptimal arousal.

\section{Cortisol}

Not all hormones are involved in sexual differentiation. Several so-called stress hormones are secreted mainly by the adrenal glands during times of anxiety, stress, and fear. The stress hormone that has been investigated most in connection with criminality is cortisol. To measure cortisol levels, blood or saliva samples are most often used, although a few investigators have used urine and cerebral spinal fluid levels. As a general rule, irregular day-to-day stress appears to result in elevated cortisol levels, which can linger in the body for hours, while stress that is sustained over several days or weeks often depletes cortisol to below-normal levels.

Five studies have compared cortisol levels of offenders and nonoffenders. Four of these indicate that offenders have below normal levels (Virkkunen 1985; King et al. 1990; Bergman and Brismar 1994; Lindman et al. 1997), while the remaining study reported no significant difference (Banks and Dabbs 1996). Psychopathy (Fishbein et al. 1992; Vanyukov et al. 1993) and drug dependency (Pajer et al. 2001) are also associated with below normal levels of cortisol.

As was asserted for heart and pulse rates and the GSR, one could anticipate a low cortisol-high criminality relationship by assuming that low cortisol production even in the face of stress is another indicator of suboptimal arousal. This would suggest that offenders are less intimidated by threatening aspects of their environments than are persons in general. Another possibility is that immunological factors (which are known to be partially regulated by cortisol) are somehow altering brain functioning in ways that are conducive to antisocial behaviour (Pajer et al. 2002).

\section{Serotonin}

Serotonin (also called 5-hydroxytryptamine or 5-HT) is an important neurotransmitter. When serotonin is relatively active in the synaptic regions connecting adjacent nerve cells, people typically report feeling a sense of contentment and calm; however, when it is inactive, reports of anxiety and depression are common (Kalus et al. 1989; Plaznik et al 1989). Several drugs that have been designed to treat depression and anxiety disorders operate by either prolonging the presence of serotonin in the synaptic gaps between neurones or by facilitating the ability of receptor sites on the 
dendrites to bond to the serotonin that is available (Fuller 1996; Mann et al. 1996).

Low serotonin activity has been linked to criminal behaviour by numerous studies (e.g., Pliszka et al. 1988; Blumensohn et al. 1995; Virkkunen et al. 1996; Matykiewicz et al. 1997). Offenders whose crimes seem to be unusually impulsive rather than being carefully planned are especially likely to exhibit serotonergic malfunctioning. Childhood conduct disorders and antisocial personality have also both been linked to below normal functioning of the serotonergic system (Coccaro et al. 1997; Dolan et al. 2002).

Explaining the link between serotonin and criminality from the perspective of ENA theory involves noting that the serotonin pathways connect the brain's prefrontal areas with the emotion-control centres in the limbic system (Davidson, Putnam and Larson 2000: 592; Strayhorn 2002: 11). A recent study of MRI scans found that compared to people in general, psychopaths had limbic systems that were relatively non-responsive to emotional stimuli and were also minimally communicating with the prefrontal areas in the frontal lobes (Kiehl et al. 2001). ENA theory implies that serotonin facilitates the sort of executive cognitive functioning required to restrain impulsive behaviour, especially impulsive responses to rage and persistent frustration.

\section{Monoamine oxidase}

Monoamine oxidase (MAO) is an enzyme found throughout the body. Within the brain, MAO helps to break down and clear away neurotransmitter molecules (including serotonin), portions of which often linger in the synaptic gap after activating adjacent nerve cells (Westlund et al. 1985).

MAO exists in two slightly different forms, MAO-A and MAO-B. Brain levels of MAO are nearly always inferred by measuring MAO activity in the blood, called platelet MAO. While this sampling source is not ideal for making inferences about MAO's behavioural effects, research has indicated that at least in the case of MAO-B, brain and platelet MAO activities are highly correlated (Bench et al. 1991).

Studies indicate that MAO activity is inversely linked to offending rates (e.g., Alm et al. 1996; af Klinteberg 1996) as well as to antisocial personality (Samochowiec et al. 1999). In addition, low MAO activity has been found statistically associated with such offence-related behaviours as impulsiveness (Manuck et al. 2000), general aggression (Manuck et al. 2000), and driving while drunk (Eensoo et al. 2004). 
While linkages between MAO brain activity and any behaviour patterns are not entirely understood, ENA theory would draw attention to the fact that nearly all of the behaviour patterns associated with low MAO activity are predominantly male patterns, and therefore may be ultimately linked to testosterone (Ellis 1991). A related possibility is that low MAO brain activity interferes with the brain's ability to manufacture or utilize serotonin, a correlate of crime mentioned earlier (see Oreland et al. 1999).

\section{Brain waves and low P300 amplitude}

Brain waves are typically measured using electrodes placed on the scalp. These electrodes can detect electrical activity occurring close to the outer surface of the brain fairly clearly. Despite their complexity, brain waves can be roughly described as ranging from being rapid and regular (alpha brain waves) to being slow and irregular (delta brain waves).

Five studies based on electroencephalographic (EEG) readings have found that offenders have slower brain waves than do persons in general (Verdeaux and Verdeaux 1955; Low and Dawson 1961; Okasha et al. 1975: 39; Mednick et al. 1981; Petersen et al. 1982), although one study failed to replicate this finding (Raine et al. 1995). Most studies of childhood conduct disorders and antisocial personality have reached a similar conclusion (reviewed by Ellis 2000: 104). In other words, most research indicates that compared to persons in general, greater proportions of the brain waves of persons who have been involved in criminal and/or antisocial behaviour are in the slow (delta and theta) range under identical testing conditions.

Unlike traditional brain wave measurement, modern computerized brain wave detection is able to compute an average response to dozens of identical stimuli. This reveals a distinctive brain wave pattern or 'signature' for each individual. Nearly everyone exhibits a noticeable spike in electrical voltage, interrupted by a 'dip' approximately one-third of a second following presentation of test stimuli. This is called the P300 amplitude of an event-related evoked potential. From a cognitive standpoint, the P300 amplitude is thought to reflect neurological events central to attention and memory (Polich 1998).

While research has been equivocal thus far in the case of criminality (Branchey et al. 1988), several studies have found a greater dip in P300 responses by individuals diagnosed with antisocial conduct disorders than is true for general populations (Raine and Venables 1988; Raine, O'Brien, Smiley, Scerbo and Chan 1990; Bauer 1997; Costa et al. 2000). A similar average decrement was also observed among a sample of alcoholics and 
their close genetic relatives (Hesselbrock et al. 2001), noteworthy in the present context because of a well-established relationship between alcoholism and criminality (Ellis and Walsh 2000: 238).

ENA theory can account for slower EEG patterns among offenders and a P300 decrement among persons with antisocial behaviour in terms of neurological arousal. More precisely, because the brains of offence-prone individuals tend to be suboptimally aroused, they are more likely than persons in general to seek intense environmental stimulation. From a neurological standpoint, both slow brain waves and a tendency toward a greater than normal P300 decrement can be considered symptomatic of suboptimal arousal. If ENA theory is correct, both of these conditions will be found associated with elevated brain exposure to testosterone or its metabolites.

\section{Summary and conclusions}

Unlike social environmental theories, the evolutionary neuroandrogenic (ENA) theory can account for statistical associations between biological variables and criminal behaviour. Furthermore, ENA theory predicts the universal concentration of offending among males between the ages of 13 and 30 , a pattern that strictly environmental theories have always had difficulty explaining.

As its name implies, ENA theory rests on two under-girding propositions. The first proposition is an extension of Darwin's theory of evolution by natural selection. It maintains that males on average exhibit competitive/ victimizing behaviour more than females because females who prefer to mate with such males increase their chances of having mates who are competent providers of resources. These female choices have evolved because females who have had the assistance of competent providers have left more offspring in subsequent generations than other females. No comparable reproductive advantage comes to males who select mates based on resource procurement capabilities.

Some forms of competitive/victimizing behaviour are crude in that they require little skill or learning; nearly all of these are assaultive or confiscatory behaviours. Other forms are sophisticated in that they require complex learning and involve much more subtle types of victimization. Examples of sophisticated competitive/victimizing behaviour arise in the context of profitable business ventures and the management of large organizations. In most societies, these are tolerated and indeed encouraged. By contrast, most people in all societies condemn the crudest expressions of 
competitive/victimizing behaviour, and the criminal justice system has evolved to punish such behaviour.

The second proposition that under-girds the theory is that genes that have evolved on the Y-chromosome cause male brains to develop differently from female brains, leading to higher rates of competitive/victimizing behaviour. These genes operate in part by causing would-be ovaries to develop instead into testes early in foetal development. Once differentiated, the testes produce testosterone and other sex hormones, which have three hypothesized effects upon brain functioning, all of which promote competitive/victimizing behaviour. The three effects are termed suboptimal arousal, proneness to seizures, and a rightward shift in neocortical functioning. Furthermore, two neurological processes are hypothesized to help individuals shift from crude to sophisticated forms of competitive/ victimizing behaviour. These are learning ability (or intelligence) and executive cognitive functioning (or planning ability). The higher or more efficient these latter two traits are, the more quickly individuals will shift from crude to sophisticated forms of the behaviour.

To illustrate the theory's predictive power, the second portion of this article reviewed evidence regarding 12 biological correlates of criminal behaviour. The theory was able to explain the relation between each of these biological features and persistent criminal offending involving attacks on people and physical property.

Overall, ENA theory is proposed to help move criminology beyond strictly social environmental theories toward a new, more variable-rich paradigm. ENA theory envisions criminality as resulting from a complex, but still comprehensible, interaction between biological factors resulting from evolutionary history, learning, and social environmental factors. Decades of hypothesis-testing will be needed to fully assess its strengths and weaknesses.

\section{Acknowledgement}

Appreciation is extended to Myrna Nelson for numerous constructive comments.

\section{References}

Adlersberg, J. and Dolger, J. (1939). Medico-legal problems of hypoglycemic reactions in diabetes. Annals of Internal Medicine 12, 1804-7.

af Klinteberg, B. (1996). Biology, norms, and personality: A developmental perspective. Neuropsychobiology 34, 146-454.

Alm, P. O., af Klinteberg, B., Humble, K., Leppert, J., Sorensen, S., Thorell, L. H., 
Lidberg, L., and Oreland, L. (1996). Psychopathy, platelet MAO activity and criminality among former juvenile delinquents. Acta Psychiatrica Scandinavica 94, 105-11.

Anderson, B. J., Holmes, M. D. and Ostresh, E. (1999). Male and female delinquents' attachments and effects of attachments on severity of self-reported delinquency. Criminal Justice and Behavior 26(4), 435-52.

Badger, K., Simpson Craft, R. and Jensen, L. (1998). Age and gender differences in value orientation among American adolescents. Adolescence 33, 591-6.

Bagley, C. (1992). Maternal smoking and deviant behavior in 16 year olds: A personality hypothesis. Personality and Individual Differences 13, 377-8.

Banks, T. and Dabbs, J. Jr. (1996). Salivary testosterone and cortisol in a delinquent and violent urban subculture. Journal of Social Psychology 136, 49-56.

Barkley, R. A. (1990). Attention deficit hyperactivity disorder: A handbook for diagnosis and treatment. New York: Guilford.

Barkley, R. A., Godzinsky, G. and DePaul, G. (1992). Frontal lobe functions in attention deficit disorder with and without hyperactivity: A review and research report. Journal of Abnormal Child Psychology 20, 163-88.

Bauer, L. O. (1997). Frontal P300 decrements, childhood conduct disorder, family history, and the prediction of relapse among abstinent cocaine abusers. Drug and Alcohol Dependence 44, 1-10.

Bench, C. J., Price, G. W., Lammertsmaa, A. A., Cremer, J. C., Luthra, S. K., Turton, D., Dolan, R. J., Kettler, R., Dingemanse, J., Da Prada, M., Biziere, K., McClelland, G. R., Jamieson, V. L., Wood, N. D. and Frackowiak, R. S. J. (1991). Measurement of human cerebral monoamine oxidase type B (MAO-B) activity with positron emission tomography (PET): A dose ranging study with the reversible inhibitor RO 19-6327. European Journal of Clinical Pharmacology 40, 169-73.

Berenson, A. B., Wiemann, C. M., Wilkinson, G. S., Jones, W. A. and Anderson, G. D. (1994). Perinatal morbidity associated with violence experienced by pregnant women. American Journal of Obstetrics and Gynecology 170, 1760-9.

Bergman, B. and Brismar, B. (1994). Hormone levels and personality traits in abusive and suicidal male alcoholics. Alcoholism: Clinical and Experimental Research 18, 311-16.

Bhasin, S., Storer, T. W., Berman, N., Callegari, C., Clevenger, B., Phillips, J., Bunnell, T., Tricker, R., Shirazi, A. and Casaburi, R. (1996). The effects of supraphysiologic doses of testosterone on muscle size and strength in normal men. New England Journal of Medicine 335, 1-7.

Blumensohn, R., Ratzoni, G., Weizman, A., Israeli, M., Greuner, N., Apter, A., Tyano, S. and Biegon, A. (1995). Reduction in serotonin 5HT receptor binding on platelets of delinquent adolescents. Psychopharmacology 118, 354-6.

Bonnet, P. L. and Pfeiffer, C. C. (1978). Biochemical diagnosis for delinquent behavior. In L. J. Hippchen (ed.) Ecologic-biochemical approaches to treatment of delinquents and criminals, 183-205. New York: van Nostrand Reinhold.

Branchey, M. H., Buydens-Branchey, L. and Lieber, C. S. (1988). P3 alcoholics with disordered regulation of aggression. Psychiatry Research 25, 49-58. 
Brennan, P. A., Grekin, E. R. and Mednick, S. A. (1999). Maternal smoking during pregnancy and adult male criminal outcomes. Archives of General Psychiatry 56, 215-24.

Buikhuisen, W., Eurelings-Bontekoe, E. H. M. and Host, K. B. (1989). Crime and recovery time: Mednick revisited. International Journal of Law and Psychiatry 12, 29-40.

Burr, C. (1993). Homosexuality and biology. Atlantic Monthly 271(March), 47-65.

Buss, D. M., Abbott, M., Angleitner, A., Asherian, A., Biaggio, A. and BlancoVillasenor, A. (1990). International preferences in selecting mates: A study of 37 cultures. Journal of Cross-cultural Psychology 21, 5-47.

Castellanos, F. X., Lee, P. P., Sharp, W., Jeffries, N. O., Greenstein, D. K., Clasen, L. S., Blumenthal, J. D., James, R. S., Ebens, C. L., Walter, J. M., Zijdenbos, A., Evans, A. C., Giedd, J. N. and Rapoport, J. L. (2002). Developmental trajectories of brain volume abnormalities in children and adolescents with attention-deficit/hyperactivity disorder. Journal of the American Medical Association 288, 1740-8.

Chollar, S. (1988). Food for thought. Psychology Today 22 (April), 30-4.

Coccaro, E. F., Kavoussi, R. J., Cooper, T. B. and Hauger, R. L. (1997). Central serotonin activity and aggression: Inverse relationship with prolactin response to d-fenfluramine, but not CSF 5-HIAA concentration in human subjects. American Journal of Psychiatry 154, 1430-5.

Comings, D. E., MacMurray, J., Johnson, P., Dietz, G. and Muhelman, D. (1995). Dopamine D2 receptor gene (DRD2) haplotypes and the defense style questionnaire in substance abuse, Tourette's syndrome, and controls. Biological Psychiatry 37, 798-805.

Compaan, J. C., van Wattum, G., de Ruiter, A. J. H., van Oortmerssen, G. A., Koolhaas, J. M. and Bohus, B. (1993). Genetic differences in female house mice in aggressive response to sex steroid hormone treatment. Physiology and Behavior 54, 899-902.

Costa, E. T., Savage, D. D. and Valenzuela, C. F. (2000). A review of the effects of prenatal or early postnatal ethanol exposure on brain ligand-gated ion channels. Alcoholism: Clinical and Experimental Research 24(5), 706-15.

Creaby, M., Warner, M., Jamil, N. and Jawad, S. (1993). Ictal aggression in severely mentally handicapped people. Irish Journal of Psychological Medicine 10, 12-15.

Cummings, J. L. (1985). Clinical neuropsychiatry. Orlando, FL: Grune and Stratton.

Davidson, H., Cave, K. R. and Sellner, D. (2000). Differences in visual attention and task interference between males and females reflect differences in brain laterality. Neuropsycholgia 38, 508-19.

Davidson, R. J., Putnam, K. M. and Larson, C. L. (2000). Dysfunction in the neural circuitry of emotion regulation: A possible prelude to violence. Science 289, 591-4.

Davis, S. (1990). Men as success objects and women as sex objects: A study of personal advertisements. Sex Roles 23, 43-50.

De Riu, P. L., Mameli, P., Bacciu, A., Simula, M. E. and Mameli, O. (1995). Effect of fetal hypoxia on seizure susceptibility in rats. Physiology and Behavior 57, 315-18. 
Dolan, M., Deakin, W. J. F., Roberts, N. and Anderson, I. (2002). Serotonergic and cognitive impairment in impulsive aggressive personality disordered offenders: Are there implications for treatment? Psychological Medicine 32, 105-17.

Eensoo, D., Paaver, M., Pulver, A., Harro, M. and Harro, J. (2004). Low platelet MAO activity associated with high dysfunctional impulsivity and antisocial behavior: Evidence from drunk drivers. Psychopharmacology 172, 356-8.

Ellis, L. (1987). Neurohormonal bases of varying tendencies to learn delinquent and criminal behavior. In E. K. Morris and C. J. Braukmann (eds) Behavioral approaches to crime and delinquency, 499-518. New York: Plenum.

Ellis, L. (1989). Theories of rape: Inquiries into the causes of sexual aggression. New York: Hemisphere.

Ellis, L. (1990). The evolution of collective counterstrategies to crime: From the primate control role to the criminal justice system. In L. Ellis and H. Hoffman (eds) Crime in biological, social, and moral contexts, 81-99. New York: Praeger.

Ellis, L. (1991). Monoamine oxidase and criminality: Identifying an apparent biological marker for antisocial behavior. Journal of Research on Crime and Delinquency 28, 227-51.

Ellis, L. (1994). Relationships between height, health, and social status (plus birth weight, mental health, intelligence, brain size, and fertility): A broad theoretical integration. In L. Ellis (ed.) Social stratification and socioeconomic inequality, 145-63. Westport, CT: Praeger.

Ellis, L. (1995). Dominance and reproductive success among nonhuman animals: A cross-species comparison. Ethology and Sociobiology 16, 257-333.

Ellis, L. (2000). Criminology: A global perspective, supplemental tables, and references. Minot, ND: Pyramid Press; URL: http://www.abacon.com/ellis/

Ellis, L. (2001). The biosocial female choice theory of social stratification. Social Biology 48, 297-319.

Ellis, L. and Ames, M. A. (1987). Neurohormonal functioning and sexual orientation: A theory of homosexuality-heterosexuality. Psychological Bulletin 101, 233-58.

Ellis, L. and Walsh, A. (2000). Criminology: A global perspective. Boston, MA: Allyn and Bacon.

Ellis, L. and Walsh, A. (2003). Crime, delinquency, and intelligence: A review of the worldwide evidence. In H. Nyborg (ed.) The scientific study of general intelligence: Tribute to Arthur R. Jensen. New York: Elsevier.

Farrington, D. P. (1997). The relationship between low resting heart rate and violence. In A. Raine, P. A. Brennan, D. P. Farrington and S. A. Mednick (eds) Biosocial bases of violence, 89-105. New York: Plenum.

Fernando, G. P. S. (1965). The incidence of psychiatric ill-health in a delinquent child population. Probation and Child Care Journal 4, 21-3.

Fidelman, U. (1992). Intelligence and the brain's energy consumption: What is intelligence? Personality and Individual Differences 14, 283-6.

Fishbein, D. (2003). Neuropsychological and emotional regulatory processes in antisocial behavior. In A. Walsh and L. Ellis (eds) Biosocial criminology: Challenging environmentalism's supremacy, 185-208. New York: Nova Science. 
Fishbein, D. H., Dax, E., Lozovsky, D. B. and Jaffe, J. H. (1992). Neuroendocrine responses to a glucose challenge in substance users with high and low levels of aggression, impulsivity, and antisocial personality. Neuropsychobiology 25, 106-14.

Fox, R. S. and Lippert, W. (1963). Spontaneous GSR and anxiety level in psychopathic delinquents. Journal of Consulting Psychology 27, 368.

Fuller, R. W. (1996). The influence of fluoxetine on aggressive behavior. Neuropsychopharmacology 14, 77-81.

Fuster, J. M. (1995). Memory and planning: Two temporal perspectives of frontal lobe function. In H. H. Jasper, S. Riggio and P. S. Goldman-Rakic (eds) Epilepsy and the functional anatomy of the frontal lobe, 9-18. New York: Raven.

Gibson, C. L. and Tibbetts, S. G. (1998). Interaction between maternal cigarette smoking and apgar scores in predicting offending behavior. Psychological Reports 83, 579-86.

Gibson, C. L., Piquero, A. R. and Tibbetts, S. G. (2000). Assessing the relationship between maternal cigarette smoking during pregnancy and age at first police contact. Justice Quarterly 17, 519-42.

Gilligan, C. (1982). In a different voice: Psychological theory and women's development. Cambridge: Harvard University Press.

Groesbeck, C., D’Asaro, B. and Nigro, C. (1975). Polyamine levels in jail inmates. Orthomolecular Psychiatry 4, 149-52.

Gross, H. and Kaltenback, E. (1975). Epilepsie und deliktisches aggressivverhalten. Nervenarzi 46, 472-4.

Hare, R. D. (1982). Psychopathy and physiological activity during anticipation of an aversive stimulus in a distraction paradigm. Psychophysiology 19, 266-71.

Hartl, E. M., Monnelli, E. T. and Eldeken, R. D. (1982). Physique and delinquent behavior. New York: Academic Press.

Hesselbrock, V., Begleiter, H., Porjesz, B., O’Connor, S. and Bauer, L. (2001). P300 event-related potential amplitude as an endophenotype of alcoholism: Evidence from the collaborative study on the genetics of alcoholism. Journal of Biomedical Science 8, 77-82.

Kalus, O., Asnis, G. M. and Van Praag, H. M. (1989). The role of serotonin in depression. Psychiatric Annals 19, 348-53.

Kandel, E. and Freed, D. (1989). Frontal-lobe dysfunction and antisocial behavior: A review. Journal of Clinical Psychology 45, 404-13.

Kemper, T. D. and Bologh, R. W. (1980). The ideal love object: Structural and family sources. Journal of Youth and Adolescence 9, 33-48.

Kiehl, K. A., Smith, A. M., Hare, R. D., Mendrek, A., Forster, B. B., Brink, J. and Liddle, P. F. (2001). Limbic abnormalities in affective processing by criminal psychopaths as revealed by functional magnetic resonance imaging. Biological Psychiatry 50, 677-84.

Kindlon, D. J., Tremblay, R. E., Mezzacappa, E., Earls, F., Laurent, D. and Schaal, B. (1995). Longitudinal patterns of heart rate and fighting behavior in 9through 12-year-old boys. Journal of the American Academy of Child and Adolescent Psychiatry 34, 371-7.

King, R. J., Jones, J., Scheuer, J. W., Curtis, D. and Zarcone, V. P. (1990). Plasma 
cortisol correlates of impulsivity and substance abuse. Personality and Individual Differences 11, 287-91.

Lanska, M. J. and Lanska, D. J. (1996). Neonatal seizures in the United States: Results of the National Hospital Discharge Survey, 1980-1991. Neuroepidemiology 15, 117-25.

Lindman, R. E., Aromaki, A. S. and Eriksson, C. J. P. (1997). Sober-state cortisol as a predictor of drunken violence. Alcohol and Alcoholism 32, 621-6.

Low, N. and Dawson, S. (1961). Electroencephalographic findings in juvenile delinquency. Pediatrics 28, 452-7.

Mann, J. J. (1995). Violence and aggression. In Bloom and Kupfer (eds) Psychopharmacology, 1919-28. New York: Raven Press, Ltd.

Mann, J. J., Malone, K. M., Diehl, D. J., Perel, J., Cooper, T. B. and Mintun, M. A. (1996). Demonstration in vivo of reduced serotonin responsivity in the brain of untreated depressed patients. American Journal of Psychiatry 153, 174-82.

Manuck, S. B., Flory, J. D., Ferrell, R. E., Mann, J. J. and Muldoon, M. F. (2000). A regulatory polymorphism of the monoamine oxidase: A gene may be associated with variability in aggression, impulsivity, and central nervous system serotonergic responsivity. Psychiatry Research 95(1), 9-23.

Matykiewicz, L., La Grange, L., Vance, P., Wang, M. and Reyes, E. (1997). Adjudicated adolescent males: Measures of urinary 5-hydroxyindoleacetic acid and reactive hypoglycemia. Personality and Individual Differences 22, 327-32.

Maughan, B., Taylor, A., Caspi, A. and Moffitt, T. E. (2004). Prenatal smoking and early childhood conduct problems: Testing genetic and environmental explanations of the association. Archives of General Psychiatry 61, 836-43.

Mednick, S. A., Volavka, J., Gabrielli, W. F., Jr. and Itil, T. M. (1981). EEG as a predictor of antisocial behavior. Criminology 19, 219-29.

Mendez, M. F., Doss, R. C. and Taylor, J. (1993). Interictal violence in epilepsy: Relationship to behavior and seizure variables. Journal of Nervous and Mental Disease 181, 566-9.

Mezzacappa, E., Tremblay, R. E., Kindlon, D., Saul, J. P., Arseneault, L., Seguin, J., Pihl, R. O. and Earls, F. (1997). Anxiety, antisocial behavior, and heart rate regulation in adolescent males. Journal of Psychiatry 38, 457-69.

Miller, B. L., Darby, A., Benson, D. F., Cummings, J. L. and Miller, M. H. (1997). Aggressive, socially disruptive and antisocial behaviour associated with fronto-temporal dementia. British Journal of Psychiatry 170, 150-5.

Moll, J., Oliveira-Souza, R., Eslinger, P. J., Bramanti, B. E., Mourao-Miranda, J., Andreiuolo, P. A. and Pessoa, L. (2002). The neural correlates of moral sensitivity: A functional magnetic resonance imaging investigation of basic and moral emotions. Journal of Neuroscience 22, 2730-6.

Mungas, D. (1983). An empirical analysis of specific syndromes of violent behavior. The Journal of Nervous and Mental Disease 171, 354-61.

Muramatsu, T., Higuchi, S., Murayama, M., Matsushita, S. and Hayashida, M. (1996). Association between alcoholism and the dopamine D4 receptor gene. Journal of Medical Genetics 33, 113-15.

Neubauer, A. C., Grabner, R. H., Freudenthaler, H. H., Beckmann, J. F. and Guthke, J. (2004). Intelligence and individual differences in becoming neurally efficient. Acta Psychologica 116, 55-74. 
Okasha, A., Sadek, A. and Moneom, S. A. (1975). Psychosocial and electroencephalographic studies of Egyptian murderers. British Journal of Psychiatry 126, 34-40.

Oreland, L, Garpenstrand, H., Damberg, M., Alm, P. O., Thorell, L-H., af Klinteberg, B. and Ekblom, J. (1999). The correlation between platelet MAO activity and personality - the effect of smoking and possible mechanism behind the correlation. Neurobiology 7, 191-203.

Pajer, K., Gardner, W., Kirillova, G. and Vanyukov, M. (2001). Sex differences in cortisol level and neurobehavioral disinhibition in children of substance abusers. Journal of Child and Adolescent Substance Abuse 10, 95-106.

Pajer, K., Rabin, B. and Gardner, W. (2002). Increased IgG 3-4 ratios in adolescent antisocial females: Evidence of Th1/Th2 imbalance? Brain, Behavior, and Immunity 16, 747-56.

Petersen, K. G. I., Matousek, M., Mednick, S. A., Volovka, J. and Pollock, V. (1982). EEG antecedents of thievery. Acta Psychiatrica Scandinavica 65, 331-8.

Plaznik, A., Kostowski, W. and Archer, T. (1989). Serotonin and depression: Old problems and new data. Progress in Neuro-Psychopharmacology and Biochemical Psychiatry 13, 623-33.

Pliszka, S. R., Rogeness, G. A., Renner, P., Sherman, J. and Broussard, T. (1988). Plasma neurochemistry in juvenile offenders. Journal of the American Academy of Child and Adolescent Psychiatry 27, 588-94.

Polich, J. (1998). P300 clinical utility and control of variability. Journal of Clinical Neurophysiology 15, 14-33.

Polich, J. and Kok, A. (1995). Cognitive and biological determinants of P300: An integrative review. Biological Psychology 41, 103-46.

Pontius, A. A. (2004). Violence in schizophrenia versus limbic psychotic trigger reaction: Prefrontal aspects of volitional action. Aggression and Violent Behavior 9, 503-21.

Pritchard, W. S. (1991). The link between smoking and P: A serotonergic hypothesis. Personality and Individual Differences 12, 1187-204.

Raine, A. (1988). Evoked potentials and psychopathy. In T. E. Moffitt and S. A. Mednick (eds) Biological contributions to crime causation, 14-39. The Netherlands: Martinus Nijhoff.

Raine, A. (1993). The psychopathology of crime: Criminal behavior as a clinical disorder. San Diego, CA: Academic Press.

Raine, A. and Jones, F. (1987). Attention, autonomic arousal, and personality in behaviorally disordered children. Journal of Abnormal Child Psychology 15, 583-99.

Raine, A. and Venables, P. H. (1984). Tonic heart rate level, social class, and antisocial behavior. Biological Psychology 18, 123-32.

Raine, A. and Venables, P. H. (1988). Enhanced P3 evoked potentials and longer P3 recovery times in psychopaths. Psychophysiology 25, 30-8.

Raine, A., Venables, P. H. and Williams, M. (1990a). Autonomic orienting responses in 15-year-old male subjects and criminal behavior at age 24 . American Journal of Psychiatry 147, 933-7.

Raine, A., Venables, P. H. and Williams, M. (1990b). Relationships between central and autonomic measures of arousal at age 15 years and criminality at age 25 years. Archives of General Psychiatry 47, 1003-7. 
Raine, A., Venables, P. H. and Williams, M. (1996). Better autonomic conditioning and faster electrodermal half-recovery time at age 15 years as possible protective factors against crime at age 29 years. Developmental Psychology 32, 624-30.

Raine, A., Phil, D., Venables, P. H. and Williams, M. (1995). High autonomic arousal and electrodermal orienting at age 15 years as protective factors against crime development at age 29 years. American Journal of Psychiatry 152, 1595-600.

Raine, A., O’Brien, M., Smiley, N., Scerbo, A. S. and Chan, C. J. (1990). Reduced lateralization in verbal dichotic listening in adolescent psychopaths. Journal of Abnormal Psychology 99, 272-7.

Rantakallio, P., Myhrman, A. and Koiranen, M. (1995). Juvenile offenders, with special reference to sex differences. Social Psychiatry and Psychiatric Epidemiology 30, 113-20.

Rantakallio, P., Laara, E., Isohanni, M. and Moilanen, I. (1992). Maternal smoking during pregnancy and delinquency of the offspring: An association without causation? International Journal of Epidemiology 21, 1106-13.

Rasanes, P., Hakko, H., Isohanni, M., Hodgins, S., Jarvelin, M.-R. and Tiihonen, J. (1999). Maternal smoking during pregnancy and risk of criminal behavior among adult male offspring in the Northern Finland 1966 birth cohort. American Journal of Psychiatry 156, 857-62.

Reite, M., Cullum, C. M., Stocker, J., Teale, P. and Kozora, E. (1993). Neuropsychological test performance and MEG-based brain lateralization: Sex differences. Brain Research Bulletin 32, 325-8.

Rogeness, G. A., Cepeda, C., Macedo, C. A., Fischer, C. and Harris, W. R. (1990b). Differences in heart rate and blood pressure in children with conduct disorder, major depression, and separation anxiety. Psychiatry Research 33, 199-206.

Rose, D. F., Smith, P. D. and Sato, S. (1987). Magnetoencephalography and epilepsy research. Science 238, 329-35.

Samochowiec, J., Lesch, K. P., Rottman, M., Smolka, M., Syagailo, Y. V., Okladnova, O., Rommelspacher, H., Winterer, G., Schmidt, L. G. and Sander, T. (1999). Association of a regulatory polymorphism in the promoter region of the monamine oxidase: A gene with antisocial alcoholism. Psychiatric Research 86, 67-72.

Sanchez-Martin, J. R., Fano, E., Ahedo, L., Cardas, J., Brain, P. F. and Azpiroz, A. (2000). Relating testosterone levels and free play social behavior in male and female preschool children. Psychoneuroendocrinology 25, 773-83.

Schoenemann, P. T., Budinger, T. F., Sarich, V. M. and Wang, W. S.-Y. (2000). Brain size does not predict general cognitive ability within families. Proceedings of the National Academy of Sciences 97, 4932-7.

Shoe, E. E., Pratt, M. W., Matthews, M. and Curror, S. E. (1996). The ethic care: Stability over time gender differences and correlates in mid to late adulthood. Psychological Aging 11, 280-92.

Shucard, J. L., Shucard, D. W. and Cummings, K. R. (1981). Auditory evoked potentials and sex-related differences in brain development. Brain and Language 13, 91-102. 
Siddle, D. A., Mednick, S. A., Nicol, A. R. and Foggitt, R. H. (1976). Skin conductance recovery in antisocial adolescents. British Journal of Social and Clinical Psychology 15, 425-8.

Smith, M. D., Jones, L. S. and Wilson, M. A. (2002). Sex differences in hippocampal slice excitability: The role of testosterone. Neuroscience and Behavioral Reviews 109, 517-30.

Soler, H., Vinayak, P. and Quadagno, D. (2000). Biosocial aspects of domestic violence. Psychoneuroendocrinology 25, 721-39.

Strayhorn, J. M. (2002). Self-control: Theory and research. Journal of the American Academy of Child and Adolescent Psychiatry 41, 7-16.

Thornhill, R. and Palmer, C. T. (2000). A natural history of rape: Biological bases of sexual coercion. Cambridge, MA: MIT Press.

Thornton, J. and Goy, R. W. (1986). Female-typical sexual behavior of rhesus and defeminization by androgens given prenatally. Hormones and Behavior 20, 129-47.

Tomarken, A. J. and Keener, A. D. (1998). Frontal brain asymmetry and depression: A self-regulatory perspective. Cognition and Emotion 12, 387-420.

Vanyukov, M. M., Moss, H. B., Plail, J. A., Blackson, T., Mezzich, A. C. and Tarter, R. E. (1993). Antisocial symptoms in preadolescent boys and in their parents: Associations with cortisol. Psychiatry Research 46, 9-17.

Verdeaux, G. and Verdeaux, J. (1955). Étude electro-encephalographic d'un groupe important de delinquants primaires ou recidvistes au cours de leur detention. Annals Medico-psychologiques 113, 643-58.

Virkkunen, M. (1982). Reactive hypoglycemic tendency among habitually violent offenders: A further study by means of the glucose tolerance test. Neuropsychobiology 5, 35-40.

Virkkunen, M. (1983). Insulin secretion during the glucose tolerance test in antisocial personality. British Journal of Psychiatry 142, 598-604.

Virkkunen, M. (1985). Urinary free cortisol excretion in habitually violent offenders. Acta Psychiatrica Scandinavica 72, 40-4.

Virkkunen, M. (1986). Reactive hypoglycemic tendency among habitually violent offenders. Nutrition Reviews 44(Supplement), 94-103.

Virkkunen, M. (1988). Cerebrospinal fluid: Monoamine metabolites among habitually violent and impulsive offenders. In T. E. Moffitt and S. A. Mednick (eds) Biological contributions to crime causation, 147-57. Boston, MA: Martinus Nijhoff.

Virkkunen, M., and Huttunen, M. O. (1982). Evidence for abnormal glucose tolerance test among violent offenders. Nsuropsychobiology 8, 30-4.

Virkkunen, M., Eggert, M., Rawlings, R. and Linnoila, M. (1996). A perspective follow-up study of alcoholic violent offenders and fire starters. Archives of General Psychiatry 53, 523-9.

Wadsworth, M. E. J. (1976). Delinquency, pulse rate and early emotional deprivation. British Journal of Criminology 16, 245-56.

Westlund, K. N. Denney, R. M., Kochersperger, L. M., Rosa, R. M. and Abell, C. W. (1985). District monoamine oxidase A and B populations in primate brain. Science 230, 181-3.

Yaruara-Tobias, J. A. and Neziroglu, F. A. (1975). Violent behavior, brain dysrythmia, and glucose dysfunction: A new syndrome. Journal of Orthomolecular Psychiatry 4, 182-8. 


\section{Lee Ellis}

Lee Ellis holds a PhD from Florida State University, and has taught criminology and other courses in the sociology department at Minot State University (Minot, North Dakota) since the mid-1970s. His research extends beyond the study of criminality to include the topics of sexual orientation and social stratification. Recent publications have been on crime, delinquency, and social status, the biosocial female choice theory of social stratification, and more generally on personality and individual differences.

ellis@minotstateu.edu 